Open Access

\title{
Reduced toxicity in the treatment of locally advanced rectal cancer: a comparison of volumetric modulated arc therapy and 3D conformal radiotherapy
}

Leif Hendrik Dröge ${ }^{1}$, Hanne Elisabeth Weber ${ }^{1}$, Manuel Guhlich¹, Martin Leu', Lena-Christin Conradi², Jochen Gaedcke ${ }^{2}$, Steffen Hennies ${ }^{1,3}$, Markus Karl Herrmann ${ }^{1,4}$, Margret Rave-Fränk ${ }^{1}$ and Hendrik Andreas Wolff ${ }^{1,3^{*}}$

\begin{abstract}
Background: Excellent dosimetric characteristics were demonstrated for volumetric modulated arc therapy (VMAT) in preoperative chemoradiotherapy (CRT) for locally advanced rectal cancer (LARC). In a single-center retrospective analysis, we tested whether these advantages may translate into significant clinical benefits. We compared VMAT to conventional 3D conformal radiotherapy (3DCRT) in patients, homogeneously treated according to the control arm of the CAO/ARO/AIO-04 trial.

Methods: CRT consisted of pelvic irradiation with $50.4 / 1.8$ Gy by VMAT $(n=81)$ or 3DCRT $(n=107)$ and two cycles of 5-fluorouracil. Standardized total mesorectal excision surgery was performed within 4-6 weeks. The tumor regression grading (TRG) was assessed by the Dworak score. Acute and late toxicity were evaluated via the Common Terminology Criteria for Adverse Events and the Late effects of normal tissues scale, respectively. Side effects greater than or equal to grade 3 were considered high-grade.

Results: Median follow-up was 18.3 months in the VMAT group and 61.5 months in the 3DCRT group with no differences in TRG between them $(p=0.1727)$. VMAT treatment substantially reduced high-grade acute and late toxicity, with $5 \%$ versus $20 \%(p=0.0081)$ and $6 \%$ vs. $22 \%(p=0.0039)$, respectively. With regard to specific organs, differences were found in skin reaction $(p=0.019)$ and proctitis $(p=0.0153)$.

Conclusions: VMAT treatment in preoperative CRT for LARC showed the potential to substantially reduce high-grade acute and late toxicity. Importantly, we could demonstrate that VMAT irradiation did not impair short-term oncological results. We conclude, that the reduced toxicity after VMAT irradiation may pave the way for more efficient systemic therapies, and hopefully improved patient survival in the multimodal treatment of LARC.
\end{abstract}

Keywords: Rectal cancer, Chemoradiotherapy, 3D conformal radiotherapy, Volumetric modulated arc therapy, Tumor regression grading, Acute toxicity, Late toxicity

\footnotetext{
* Correspondence: drhawolff@googlemail.com

${ }^{1}$ Department of Radiotherapy and Radiation Oncology, University Medical

Center Göttingen, Robert-Koch-Straße 40, 37075 Göttingen, Germany

${ }^{3}$ Present address: Radiologie München, Burgstrasse 7, 80331 München, Germany

Full list of author information is available at the end of the article
}

() Biomed Central

(c) 2015 Dröge et al. Open Access This article is distributed under the terms of the Creative Commons Attribution 4.0 International License (http://creativecommons.org/licenses/by/4.0/), which permits unrestricted use, distribution, and reproduction in any medium, provided you give appropriate credit to the original author(s) and the source, provide a link to the Creative Commons license, and indicate if changes were made. The Creative Commons Public Domain Dedication waiver (http://creativecommons.org/publicdomain/zero/1.0/) applies to the data made available in this article, unless otherwise stated. 


\section{Background}

Preoperative chemoradiotherapy (CRT) for locally advanced rectal cancer (LARC), followed by standardized total mesorectal excision (TME) surgery, results in excellent local control rates, but distant failure compromises patients' survival [1, 2]. To reduce distant failure risk, clinical trials aim to intensify systemic treatment, at the hazard of increased toxicity and quality of life impairment [3-5]. Such strategy requires the optimization of any local therapy, including radiotherapy (RT), in terms of efficacy and tolerability.

Advanced RT techniques, namely intensity-modulated radiotherapy (IMRT), volumetric modulated arc therapy (VMAT), and proton therapy showed excellent target volume coverage and organs at risk sparing in dosimetric studies [6-8]. To a very limited extent, clinical studies on LARC irradiation reported enhanced tumor response [9] and reduced acute toxicity $[9,10]$ when IMRT was compared to conventional 3D conformal radiotherapy (3DCRT). A large-scale direct comparison of clinical results after VMAT and 3DCRT has not been reported to date.

Based on promising dosimetric results, VMAT was introduced to our clinic and gradually replaced 3DCRT for LARC since 2009. The purpose of the present singlecenter study was to compare VMAT-treated patients with 3DCRT-treated patients in terms of tumor response, acute and late toxicity.

\section{Methods}

\section{Patients}

The database at our institution contained 188 patients who were consecutively treated with neoadjuvant CRT and concurrent 5-fluorouracil for non-metastatic LARC from 2005 to 2014. The diagnosis was assured via rigid endoscopy with histologic sampling. The clinical tumor stage was assessed by endoscopic ultrasound and pelvic MRI scan.

All patients were treated according to the control arm of the CAO/ARO/AIO-04 trial [EudraCT no.: 2006002385-20]. This multicenter, randomized phase III trial investigated the addition of oxaliplatin to multimodal treatment of LARC. Patients were assigned to receive either standard neoadjuvant 5-fluorouracil-based CRT, TME surgery, and adjuvant 5 -fluorouracil chemotherapy (control arm), or neoadjuvant CRT with 5-fluorouracil/ oxaliplatin, TME surgery, and adjuvant 5-fluorouracil/ oxaliplatin/leucovorin (investigational arm) [4]. At our institution, all the LARC patients were highly homogeneously treated by a specialized interdisciplinary group in the context of the Clinical Research Unit 179, funded by the German Research Foundation (DFG). The investigations were conducted according to Declaration of Helsinki principles. The Ethics Committee at the University of Göttingen approved the study, and patients gave informed consent in written form.

\section{Chemoradiotherapy}

RT was applied with linear accelerator photons to a reference dose of $50.4 \mathrm{~Gy}$ in $1.8 \mathrm{~Gy}$ fractions. Patients were positioned in abdominal position on a belly board. The clinical target volume (CTV) and the organs at risk were outlined on the basis of the planning CT scan and the diagnostic MRI scan, using the Eclipse system (v8.9, Varian Medical Systems). The CTV included the primary tumor and the mesorectal, presacral and internal iliac lymph nodes [4]. The planning target volume (PTV) was defined by enlarging the CTV in all directions by $10 \mathrm{~mm}$. Patients were treated according to respective technical standards. Conventional 3DCRT was used from 2005 to 2012, while VMAT superseded 3DCRT as of 2009.

The treatment plans were calculated according to ICRU recommendations. The dose was defined at the ICRU 50 reference point. The isodose curve representing $95 \%$ of the prescribed dose had to encompass the entire PTV and the maximum dose to the PTV was limited to $<107 \%$ of the prescribed dose [11, 12]. The aim was to minimize the dose to the organs at risk, using these constraints [7]: bladder $\geq 40 \mathrm{~Gy}$ in $\leq 50 \%$ volume; small bowel $\geq 50$ Gy in $\leq 10 \mathrm{~cm}^{3}$ volume and $\geq 40$ Gy in $\leq 100 \mathrm{~cm}^{3}$ volume, whereas individual loops of small bowel were contoured.

As described before, the 3DCRT was applied using a three-field technique. The beam angles were 0,90 and $270^{\circ}$. The photon energies were $6 \mathrm{MeV}$ (beam direction, $0^{\circ}$ ) and $20 \mathrm{MeV}$ (beam directions, 90 and $270^{\circ}$ ). A multileaf collimator (Millennium 120, Varian Medical Systems) was used to shape the fields. Wedges $\left(45^{\circ}\right.$ or $\left.60^{\circ}\right)$ were used in lateral fields to obtain homogeneous dose distribution. VMAT was carried out using RapidArcœ (Varian Medical Systems) with two full arcs, and with a photon energy of $6 \mathrm{MeV}$. A single arc was arranged into 177 control points ( 1 control point about every $2^{\circ}$ of gantry) [7].

The concurrent chemotherapy for all patients consisted of 5-fluorouracil $\left(1000 \mathrm{mg} / \mathrm{m}^{2}\right.$ on days $1-5$ and 29-33 of the RT). Standardized TME surgery was performed within 4-6 weeks, followed by 4 cycles of bolus 5 -fluorouracil $\left(500 \mathrm{mg} / \mathrm{m}^{2}\right)$.

\section{Tumor response/ toxicity assessment}

The tumor staging in the resected specimen was based on the sixth edition of the TNM classification [13]. The tumor regression grading (TRG) was assessed by the quantification of the ratio of tumor tissue versus fibrotic tissue (Dworak score) [14].

Acute toxicity was assessed via the National Cancer Institute Common Terminology Criteria for Adverse Events, version 3.0 [15]. A minimum of weekly examinations by 
the treating radiation oncologist and weekly blood samples were mandatory. After CRT, patients were closely monitored for at least 2 weeks and beyond that in the case of persisting acute toxicity. Late toxicity was evaluated according to the Late effects of normal tissues scale [16]. Patients were monitored for late toxicity at 3 months, and thereafter annually for up to 5 years. Toxicity of $\geq$ grade 3 was defined as high-grade toxicity.

\section{Statistical analysis}

For the comparison of the patient characteristics, toxicity, surgery and histopathological parameters, the median and range are given for the continuous parameters while frequency and percentage are given for the categorical variables. The Chi-Square test and the KruskalWallis test were used for comparison of categorical and continuous variables. The Kaplan-Meier method was used to compare the actuarial occurrence of late toxicity. $P$-values $<0.05$ were considered statistically significant. The analyses were performed using STATISTICA (v10.0.1011.0, StatSoft. Inc.).

\section{Results}

\section{Patients}

We included 188 patients who were treated from 05/2005 to $01 / 2014$. Patient characteristics are presented in Table 1. The median patient age was 66 years (range, 35-86 years) with 64 years (range, 35-83 years) in the 3DCRT group, and 70 years (range, 43-86 years) in the VMAT group. The 3DCRT technique was used in 107 (56.9 \%) patients and the VMAT technique in 81 (43.1\%).

There were no differences in clinical T category, clinical $\mathrm{N}$ category, tumor grading and tumor distance from the anal verge. The VMAT group had a significantly larger proportion of patients with $\geq 70$ years $(p=0.0378)$ and with a lower body mass index $(p=0.0453)$.

\section{Surgery and histopathological parameters}

Surgery and histopathological data are presented in Table 2. The surgical procedures consisted of 123 low anterior resections $(65 \%)$ and 65 abdominoperineal resections (35\%). The frequency of low anterior resections and abdominoperineal resections was $68(64 \%)$ and 39 $(36 \%)$ in the 3DCRT group and $55(68 \%)$ and $26(32 \%)$ in the VMAT group, respectively. In tumors located within 0 to $<6 \mathrm{~cm}$ from the anal verge, sphincter-saving surgery was performed in $9 / 40$ patients (23\%) of the 3DCRT group and in $11 / 35$ patients (31 \%) of the VMAT group. A complete resection (R0) was achieved in 183 patients $(97 \%)$ with 104 (97 \%) in the 3DCRT group and 79 (98 \%) in the VMAT group. There were no differences regarding TRG, ypT category and ypN category.
Table 1 Patient characteristics

\begin{tabular}{|c|c|c|c|c|c|}
\hline \multirow[t]{2}{*}{ Characteristic } & \multicolumn{2}{|c|}{$\begin{array}{l}3 \mathrm{D} \text { conformal } \\
\text { radiotherapy }\end{array}$} & \multicolumn{2}{|c|}{$\begin{array}{l}\text { Volumetric modulated } \\
\text { arc therapy }\end{array}$} & \multirow[t]{2}{*}{$p$} \\
\hline & No. & $\%$ & No. & $\%$ & \\
\hline \multicolumn{6}{|l|}{ Gender } \\
\hline female & 30 & 28 & 23 & 28 & \multirow[t]{2}{*}{0.9570} \\
\hline male & 77 & 72 & 58 & 72 & \\
\hline \multicolumn{6}{|l|}{ Age, years } \\
\hline$\geq 70$ years & 38 & 36 & 41 & 51 & \multirow[t]{2}{*}{0.0378} \\
\hline$<70$ years & 69 & 64 & 40 & 49 & \\
\hline \multicolumn{6}{|c|}{ Body mass index $\left[\mathrm{kg} / \mathrm{m}^{2}\right]$} \\
\hline$<20$ & 2 & 2 & 0 & 0 & \multirow[t]{5}{*}{0.0453} \\
\hline $20-24.9$ & 32 & 30 & 24 & 30 & \\
\hline $25-26.9$ & 15 & 14 & 19 & 24 & \\
\hline $27-29.9$ & 27 & 25 & 27 & 33 & \\
\hline$\geq 30$ & 31 & 29 & 11 & 13 & \\
\hline \multicolumn{6}{|c|}{ Clinical T category } \\
\hline 2 & 2 & 2 & 2 & 3 & \multirow[t]{3}{*}{0.7843} \\
\hline 3 & 96 & 90 & 70 & 86 & \\
\hline 4 & 9 & 8 & 9 & 11 & \\
\hline \multicolumn{6}{|c|}{ Clinical N category } \\
\hline negative & 29 & 27 & 18 & 22 & \multirow[t]{2}{*}{0.4441} \\
\hline positive & 78 & 73 & 63 & 78 & \\
\hline \multicolumn{6}{|l|}{ Grading } \\
\hline$x$ & 9 & 8 & 14 & 17 & \multirow[t]{5}{*}{0.0806} \\
\hline 1 & 1 & 1 & 0 & 0 & \\
\hline 2 & 75 & 70 & 60 & 74 & \\
\hline 3 & 21 & 20 & 7 & 9 & \\
\hline 4 & 1 & 1 & 0 & 0 & \\
\hline \multicolumn{6}{|c|}{ Distance from anal verge } \\
\hline 0 to $<6 \mathrm{~cm}$ & 40 & 37 & 35 & 43 & \multirow[t]{3}{*}{0.7212} \\
\hline 6 to $<12 \mathrm{~cm}$ & 64 & 60 & 44 & 54 & \\
\hline 12 to $16 \mathrm{~cm}$ & 3 & 3 & 2 & 3 & \\
\hline
\end{tabular}

\section{Acute toxicity}

Acute organ toxicity data are presented in Table 3. Any kind of high-grade acute organ toxicity occurred in 25 of 188 patients (13\%), and was more frequent in the 3DCRT group with 21 of 107 patients (20\%) than in the VMAT group with four of 81 patients $(5 \%)(p=0.0081)$. The 3DCRT patients had a significantly higher proportion of $\geq$ grade 3 skin reaction with $7(7 \%)$ in the 3DCRT group and $0(0 \%)$ in the VMAT group $(p=0.019)$. The frequency of $\geq$ grade 3 proctitis was higher in the 3DCRT cohort with 13 (12\%) for 3DCRT patients and 2 (2\%) for VMAT patients $(p=0.0153)$. In multi-group comparison, any kind of acute organ toxicity $(p=0.0113)$ 
Table 2 Surgery and histopathologic parameters

\begin{tabular}{|c|c|c|c|c|c|}
\hline \multirow[t]{2}{*}{ Characteristic } & \multicolumn{2}{|c|}{$\begin{array}{l}\text { 3D conformal } \\
\text { radiotherapy }\end{array}$} & \multicolumn{2}{|c|}{$\begin{array}{l}\text { Volumetric } \\
\text { modulated arc } \\
\text { therapy }\end{array}$} & \multirow[t]{2}{*}{$p$} \\
\hline & No. & $\%$ & No. & $\%$ & \\
\hline \multicolumn{6}{|l|}{ OP-method } \\
\hline Low anterior resection & 68 & 64 & 55 & 68 & 0.5356 \\
\hline Abdominoperineal resection & 39 & 36 & 26 & 32 & \\
\hline
\end{tabular}

Distance from anal verge 0 to $<6 \mathrm{~cm}$, sphincter-saving surgery

$\begin{array}{cccccc}\text { Yes } & 9 & 23 & 11 & 31 & 0.3830 \\ \text { No } & 31 & 77 & 24 & 69 & \\ \text { R-status } & & & & & \\ 0 & 104 & 97 & 79 & 98 & 0.5330 \\ 1 & 1 & 1 & 2 & 2 & \\ 2 & 1 & 1 & 0 & 0 & \\ X & 1 & 1 & 0 & 0 & \end{array}$

ypT-stage

$\begin{array}{llllll}0 & 14 & 13 & 16 & 20 & 0.1397 \\ 1 & 11 & 10 & 5 & 6 & \\ 2 & 34 & 32 & 25 & 31 & \\ 3 & 42 & 39 & 35 & 43 & \\ 4 & 6 & 6 & 0 & 0 & \end{array}$

ypN-stage

$\begin{array}{llllll}0 & 69 & 65 & 57 & 70 & 0.5492 \\ 1 & 27 & 25 & 15 & 19 & \\ 2 & 11 & 10 & 9 & 11 & \end{array}$

Tumor regression grading

\begin{tabular}{llllll}
0 no regression & 0 & 0 & 1 & 1 & 0.1727 \\
1 minor regression & 12 & 11 & 9 & 11 & \\
2 moderate regression & 34 & 32 & 32 & 40 & \\
3 good regression & 47 & 44 & 23 & 28 & \\
4 total regression & 14 & 13 & 16 & 20 & \\
\hline
\end{tabular}

The Chi-Square test and the Krusal-Wallis test were used for group comparisons Abbreviations: $R$-status resection status, ypT tumor stage after preoperative radiochemotherapy, ypN nodal stage after preoperative radiochemotherapy

and the skin reaction $(p=0.0056)$ were significantly more frequent in the 3DCRT group.

Any kind of hematotoxicity (anemia, leucopenia, thrombopenia) $\geq$ grade 3 occurred in six patients $(3 \%)$ with four patients $(4 \%)$ in the 3DCRT group and two patients $(3 \%)$ in the VMAT group. The 3DCRT and VMAT group comparison showed no differences regarding hematotoxicity (Additional file 1: Table S1).

\section{Late toxicity}

Late toxicity data are presented in Table 4. Follow-up data were available for 173 patients (92\%) with 102 patients $(95 \%)$ in the 3DCRT group and 71 patients (88 \%) in the VMAT group. The median follow-up time
Table 3 Acute organ toxicity

\begin{tabular}{|c|c|c|c|c|c|c|}
\hline \multirow[t]{2}{*}{$\begin{array}{l}\text { Toxicity } \\
\text { grade }\end{array}$} & \multicolumn{2}{|c|}{$\begin{array}{l}\text { 3D conformal } \\
\text { radiotherapy }\end{array}$} & \multicolumn{2}{|c|}{$\begin{array}{l}\text { Volumetric } \\
\text { modulated } \\
\text { arc therapy }\end{array}$} & \multirow[b]{2}{*}{ Chi-square, $p$} & \multirow[b]{2}{*}{ Kruskal-Wallis, $p$} \\
\hline & No. & $\%$ & No. & $\%$ & & \\
\hline \multicolumn{7}{|c|}{ Skin reaction } \\
\hline$\geq 3$ & 7 & 7 & 0 & 0 & 0.0190 & \\
\hline 0 & 21 & 20 & 26 & 32 & & \multirow[t]{3}{*}{0.0056} \\
\hline 1 & 42 & 39 & 39 & 48 & & \\
\hline 2 & 37 & 34 & 16 & 20 & & \\
\hline 3 & 7 & 7 & 0 & 0 & & \\
\hline
\end{tabular}

Proctitis

$\begin{array}{lllll}\geq 3 & 13 & 12 & 2 & 2 \\ 0 & 15 & 14 & 9 & 1 \\ 1 & 36 & 34 & 36 & 45 \\ 2 & 43 & 40 & 34 & 42 \\ 3 & 13 & 12 & 2 & 2\end{array}$

0.0153

0.0670

Enteritis

$\begin{array}{ccccc}\geq 3 & 4 & 4 & 1 & 1 \\ 0 & 53 & 49 & 36 & 44 \\ 1 & 34 & 32 & 29 & 36 \\ 2 & 16 & 15 & 15 & 19 \\ 3 & 4 & 4 & 1 & 1\end{array}$

0.2907

0.5898

Cystitis

$\begin{array}{lllll}\geq 3 & 3 & 3 & 1 & 1 \\ 0 & 63 & 59 & 39 & 48 \\ 1 & 39 & 36 & 35 & 43 \\ 2 & 2 & 2 & 6 & 7 \\ 3 & 2 & 2 & 1 & 1 \\ 4 & 1 & 1 & 0 & 0\end{array}$

0.4603

0.2219

Balanitis

$\begin{array}{lllll}0 & 106 & 99 & 81 & 100 \\ 3 & 1 & 1 & 0 & 0\end{array}$

Any kind of acute organ toxicity ${ }^{a}$

\begin{tabular}{ccccccc}
$\geq 3$ & 21 & 20 & 4 & 5 & 0.0081 & \\
0 & 4 & 4 & 2 & 3 & & 0.0113 \\
1 & 27 & 25 & 36 & 44 & & \\
2 & 55 & 51 & 39 & 48 & & \\
3 & 20 & 19 & 4 & 5 & & \\
4 & 1 & 1 & 0 & 0 & & \\
\hline
\end{tabular}

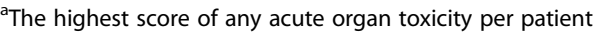

${ }^{\text {b}}$ No statistical comparisons due to small groups of patients

was 61.5 months (range, 4.0-105.7 months) in the 3DCRT group and 18.3 months (range, 4.0-59.2 months) in the VMAT group. The 2-year rates of freedom from high-grade late organ toxicity were $81 \%$ for the 3DCRT group and $91 \%$ for the VMAT group (Fig. 1). There were no differences regarding skin toxicity, proctitis 
Table 4 Late toxicity

\begin{tabular}{|c|c|c|c|c|c|c|}
\hline \multirow[t]{2}{*}{$\begin{array}{l}\text { Toxicity } \\
\text { grade }\end{array}$} & \multicolumn{2}{|c|}{$\begin{array}{l}3 \mathrm{D} \text { conformal } \\
\text { radiotherapy }\end{array}$} & \multicolumn{2}{|c|}{$\begin{array}{l}\text { Volumetric modulated } \\
\text { arc therapy }\end{array}$} & \multirow[b]{2}{*}{ Chi-square, $p$} & \multirow[b]{2}{*}{$\begin{array}{l}\text { Kruskal- } \\
\text { Wallis, } p\end{array}$} \\
\hline & No. & $\%$ & No. & $\%$ & & \\
\hline \multicolumn{7}{|l|}{ Skin } \\
\hline$\geq 3$ & 2 & 2 & 0 & 0 & 0.2353 & \\
\hline 0 & 83 & 81 & 64 & 90 & & 0.3161 \\
\hline 1 & 16 & 16 & 7 & 10 & & \\
\hline 2 & 1 & 1 & 0 & 0 & & \\
\hline 3 & 2 & 2 & 0 & 0 & & \\
\hline \multicolumn{7}{|l|}{ Proctitis } \\
\hline$\geq 3$ & 8 & 8 & 2 & 3 & 0.1635 & \\
\hline 0 & 69 & 68 & 52 & 73 & & 0.2498 \\
\hline 1 & 11 & 11 & 10 & 14 & & \\
\hline 2 & 14 & 14 & 7 & 10 & & \\
\hline 3 & 6 & 6 & 0 & 0 & & \\
\hline 4 & 2 & 2 & 2 & 3 & & \\
\hline \multicolumn{7}{|l|}{ Cystitis } \\
\hline$\geq 3$ & 10 & 10 & 2 & 3 & 0.0752 & \\
\hline 0 & 82 & 80 & 65 & 91 & & 0.2271 \\
\hline 1 & 8 & 8 & 2 & 3 & & \\
\hline 2 & 2 & 2 & 2 & 3 & & \\
\hline 3 & 9 & 9 & 2 & 3 & & \\
\hline 4 & 1 & 1 & 0 & 0 & & \\
\hline
\end{tabular}

Enteritis

\begin{tabular}{cccccc}
0 & 96 & 94 & 71 & 100 & $b$ \\
1 & 2 & 2 & 0 & 0 & \\
2 & 3 & 3 & 0 & 0 & \\
3 & 1 & 1 & 0 & 0 & \\
Lymphedema & & & & \\
0 & 101 & 99 & 71 & 100 & $b$ \\
1 & 1 & 1 & 0 & 0 & \\
Urethral stricture & & & & \\
0 & 101 & 99 & 71 & 100 & $b$ \\
3 & 1 & 1 & 0 & 0 & \\
Ureteral stenosis & & & & \\
0 & 97 & 95 & 71 & 100 & $b$ \\
3 & 5 & 5 & 0 & 0 & 0.0039 \\
Any kind of the organ toxicity & \\
$\geq 3$ & 22 & 22 & 4 & 6 & \\
0 & 44 & 43 & 47 & 66 & \\
1 & 25 & 25 & 12 & 17 & \\
2 & 11 & 11 & 8 & 11 & \\
3 & 19 & 19 & 2 & 3 \\
4 & 3 & 3 & 2 & 3 & \\
\hline
\end{tabular}

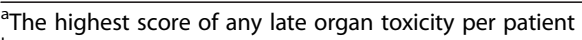

${ }^{\mathrm{b}}$ No statistical comparisons due to small groups of patients and cystitis. Additional high-grade toxicity, namely enteritis $(n=4)$, urethral stricture $(n=1)$ or ureteral stenosis $(n=5)$ occurred in 10 3DCRT patients $(10 \%)$, while none of the VMAT patients $(0 \%)$ experienced these complications. Any kind of high-grade late organ toxicity occurred in 26 patients (15\%) with 22 patients (22\%) in the 3DCRT group and four patients $(6 \%)$ in the VMAT group $(p=0.0039)$. In multi-group comparison, high-grade late organ toxicity was significantly more frequent in the 3DCRT group $(p=0.0073)$.

\section{Discussion}

The use of IMRT and VMAT in the preoperative CRT of LARC is still rare, but dosimetric studies showed excellent target volume coverage and organs at risk sparing $[7,8,10,17]$. Our group already demonstrated the superiority of VMAT over 3DCRT in a planning study with 25 patients, using the treatment protocol of the current study [7]. We analysed, whether these dosimetric advantages translate into significant clinical benefits. When directly comparing VMAT-treated patients with 3DCRT-treated patients in terms of tumor response, acute and late toxicity we found that VMAT provides equal tumor regression combined with reduced acute and late organ toxicity.

To assess tumor response, we used the standardized five-point TRG [14], and found no differences between VMAT-treated patients and 3DCRT-treated patients. Fokas et al. identified TRG as an independent prognostic factor for metastasis-free and disease-free survival of LARC patients treated according to the protocols of the CAO/ARO/AIO rectal cancer trials [18]. Thus TRG may reflect CRT effectiveness and our data could indicate that VMAT-treated patients will experience satisfying oncological outcome. This assumption is supported by a small feasibility study [6], where Richetti et al. analysed VMAT in 45 patients with preoperative CRT of LARC and demonstrated improved dose conformality and a tumor downstaging, comparable to previously published data for conventional RT. Furthermore the favorable oncological outcome in patients treated with IMRT for rectal cancer $[9,19]$ and other tumors [20-23] supports a potential benefit for VMAT-treated patients. IMRT and VMAT have comparable dosimetric characteristics [17], but IMRT is already used for quite some time and therefore patient data with longer follow up periods are available [24].

In addition, for IMRT, an excellent toxicity profile was achieved for patients with LARC $[9,10,25]$, and other tumor entities [20-23, 26]. Comparisons of IMRT with 3DCRT indicate a reduction of acute gastrointestinal toxicity and treatment breaks $[10,25]$. Since the issue has not been addressed in larger cohorts, an ongoing 


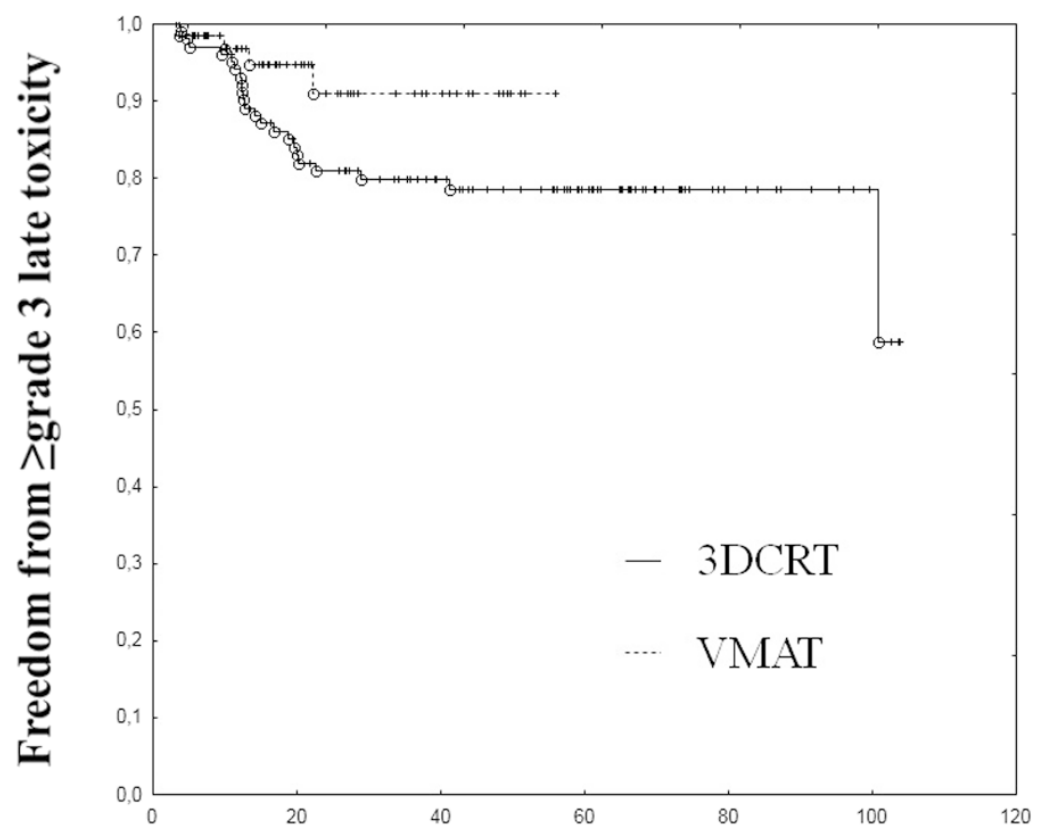

Months after completion of neoadjuvant CRT

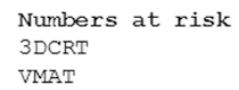

81
30

61

12
41
0
12
4

Fig. 1 Freedom from $\geq$ grade 3 late toxicity. The Kaplan-Meier method was used to compare the occurrence of late toxicity in patients who underwent neoadjuvant chemoradiotherapy (CRT) with 3D conformal radiotherapy (3DCRT) or volumetric modulated arc therapy (VMAT)

clinical trial aims to compare the acute toxicity rates after IMRT and 3DCRT [NCT02151019]. Considerable differences exist between IMRT and VMAT, namely the reduction of treatment delivery time and the number of applied monitor units $[6,27]$. Thus, the clinical comparison of VMAT and 3DCRT must be addressed separately. In general, clinical toxicity data for VMAT are scarce. A favorable acute toxicity profile was described for prostate, non-small cell lung, anal canal and endometrial cancer [28-31], and in the feasibility study of Richetti et al. for LARC [6], where high-grade acute organ toxicity occurred in three patients (7\%), only.

The current study demonstrates the potential of VMAT to substantially reduce high-grade acute organ toxicity, showing a ratio of $20 \%$ for 3DCRT versus $5 \%$ for VMAT. Well-known risk factors for the occurrence of high-grade acute organ toxicity in preoperative CRT of LARC are female gender [32], age $\geq 70$ years [33] and low body mass index [34]. In the current study, the VMAT group showed a significantly higher proportion of patients being older than 70 years and having a low body mass index. Remarkably, the VMAT treatment resulted in lower acute toxicity rates despite the preponderance of features for higher risk of toxicity.
With regard to specific organs, differences were found in high-grade skin reaction (7\% vs. $0 \%$ ) and in proctitis (12\% vs. $2 \%$ ). The reduction of skin reaction might be explained by the fact that VMAT treatment generally leads to an increase in the volume of normal tissue receiving low-dose irradiation and to a decrease in the volume of normal tissue receiving high-dose irradiation [27]. For IMRT in breast cancer treatment, a reduction in acute skin reaction in comparison to 3DCRT was demonstrated [35] where moist desquamation likely occurred in highest skin dose areas [36]. The reduction in proctitis rates was not described previously in the literature. Our group already demonstrated a significant reduction of high dose areas in the PTV with VMAT plans $\left(\mathrm{V}_{107} \%=0.1 \%\right)$ in comparison to 3DCRT plans $\left(\mathrm{V}_{107} \%=3.5 \%\right)$ [7]. The diminution of rectal high-dose areas could lead to lower rates of injury to the rectal wall.

In the current study, no differences between 3DCRT treatment and VMAT treatment were observed regarding hematotoxicity. Altogether, six patients (3\%) developed high-grade hematotoxicity. Mell et al. found the irradiated volume of pelvic bone marrow receiving lowdose irradiation to be predictive for hematotoxicity in the CRT of cervical cancer with IMRT. The authors 
argued that the use of IMRT might be suitable to reduce hematotoxicity in pelvic RT [37]. However, there are no available data comparing hematotoxicity after 3DCRT and VMAT in a similar patient population. Our findings suggest that, despite the probable increase in irradiated volume of bone marrow with VMAT in comparison to 3DCRT, there is no clinically detectable negative effect on hematotoxicity.

To our knowledge, no published data exist on the late toxicity rates after VMAT in preoperative CRT for rectal cancer. We found significantly lower rates of late toxicity for VMAT in comparison to 3DCRT. Highgrade late organ toxicity occurred in $22 \%$ of the 3DCRT patients and in $6 \%$ of the VMAT patients. Altogether, high-grade enteritis, urethral stricture or ureteral stenosis occurred in $10 \%$ of the 3DCRT patients, while none of the VMAT patients experienced these complications. In general, the small bowel and bladder complications occur after organ exposure to RT doses of $\geq 50$ Gy [38]. Especially for comparably high dose levels, our group demonstrated a remarkable improvement with VMAT. For the small bowel, the $\mathrm{V}_{40 \text { Gy }}$ was $28.4 \%$ with VMAT plans and $41.8 \%$ with 3DCRT plans. For the urinary bladder, the $\mathrm{V}_{40 \mathrm{~Gy}}$ was $66.5 \%$ with VMAT plans and $88.4 \%$ with 3DCRT plans [7]. These findings could explain the absence of enteritis, urethral stricture and ureteral stenosis in VMAT patients.

To address the limitations of the current study, though patients were treated in accordance with the respective protocol, the comparison of 3DCRT and VMAT was not a predefined endpoint of the trial. Thus, a potential bias due to covariates cannot be excluded with absolute certainty. Furthermore, due to the fact that VMAT was introduced into clinical practice only a short time ago, the groups appear different in length of follow-up. As an important concern for the late toxicity data, a prolonged observation period is required. However, the latency to the occurrence of late toxicity in preoperative CRT of LARC is less well known. After RT of cervical cancer, high rates of urinary tract and small bowel complications were found during earlier follow-up. The complication rates sharply declined after 2-3 years [39]. In the current study, 28 patients (35\%) in the VMAT group were observed for a period of $>2$ years. Since none of these patients experienced high-grade enteritis, urethral stricture or ureteral stenosis, the current findings indicate that VMAT reduces late toxicity in preoperative CRT of LARC. Nevertheless, the outstanding strength of the current study is the homogeneous treatment according to the German CAO/ARO/AIO-04 trial. The presented data highlight the benefits of the VMAT irradiation for LARC on a powerful basis.

\section{Conclusions}

In summary, VMAT treatment in preoperative CRT for LARC showed the potential to substantially reduce high-grade organ toxicity, and lower rates of late toxicity were conceivable. Importantly, we could demonstrate that VMAT irradiation did not impair short-term oncological results. We conclude, that the delivery of preoperative RT using VMAT may pave the way for more efficient systemic therapies, and improved patient survival in the multimodal treatment of LARC.

\section{Additional file}

Additional file 1: Table S1. Hematotoxicity. (PDF $41 \mathrm{~kb}$ )

\section{Abbreviations}

VMAT: Volumetric modulated arc therapy; CRT: Chemoradiotherapy; LARC: Locally advanced rectal cancer; 3DCRT: 3D conformal radiotherapy; TRG: Tumor regression grading; TME: Total mesorectal excision; RT: Radiotherapy; IMRT: Intensity-modulated radiotherapy; CTV: Clinical target volume; PTV: Planning target volume.

\section{Competing interests}

The authors declare that they have no competing interests.

\section{Authors' contributions}

LHD, ML, JG, MR-F and HAW initiated the study. HEW, MG, JG and MKH contributed to its design and coordination. LHD, MG, ML and L-CC collected the clinical data. LHD, L-CC, SH and HAW performed the statistical analysis. LHD, HEW, SH, MKH and MR-F wrote the manuscript. All authors read and approved the final manuscript.

\section{Acknowledgements}

This work was conducted within the Clinical Research Unit 179 (KFO 179), funded by the German Research Foundation (DFG).

\section{Author details}

${ }^{1}$ Department of Radiotherapy and Radiation Oncology, University Medical Center Göttingen, Robert-Koch-Straße 40, 37075 Göttingen, Germany.

Department of General, Visceral and Pediatric Surgery, University Medical Center Göttingen, Göttingen, Germany. ${ }^{3}$ Present address: Radiologie München, Burgstrasse 7, 80331 München, Germany. ${ }^{4}$ MVZ Klinik Dr. Hancken,

Strahlentherapie und Radioonkologie, Stade, Germany.

Received: 30 April 2015 Accepted: 16 October 2015

Published online: 20 October 2015

\section{References}

1. Sauer R, Liersch T, Merkel S, Fietkau R, Hohenberger W, Hess C, et al. Preoperative versus postoperative chemoradiotherapy for locally advanced rectal cancer: results of the German CAO/ARO/AIO-94 randomized phase III trial after a median follow-up of 11 years. J Clin Oncol. 2012;30(16):1926-33.

2. Engelen $S M$, Maas M, Lahaye MJ, Leijtens JW, van Berlo $C L$, Jansen $R L$, et al. Modern multidisciplinary treatment of rectal cancer based on staging with magnetic resonance imaging leads to excellent local control, but distant control remains a challenge. Eur J Cancer. 2013;49(10):2311-20.

3. Kripp M, Wieneke J, Kienle P, Welzel G, Brade J, Horisberger K, et al. Intensified neoadjuvant chemoradiotherapy in locally advanced rectal cancer - impact on long-term quality of life. Eur J Surg Oncol. 2012;38(6):472-7.

4. Rödel C, Liersch T, Becker H, Fietkau R, Hohenberger W, Hothorn T, et al. Preoperative chemoradiotherapy and postoperative chemotherapy with fluorouracil and oxaliplatin versus fluorouracil alone in locally advanced rectal cancer: initial results of the German CAO/ARO/AIO-04 randomised phase 3 trial. Lancet Oncol. 2012;13(7):679-87. 
5. An X, Lin X, Wang FH, Goodman K, Cai PQ, Kong LH, et al. Short term results of neoadjuvant chemoradiotherapy with fluoropyrimidine alone or in combination with oxaliplatin in locally advanced rectal cancer: a meta analysis. Eur J Cancer. 2013;49(4):843-51.

6. Richetti A, Fogliata A, Clivio A, Nicolini G, Pesce G, Salati E, et al. Neoadjuvant chemo-radiation of rectal cancer with volumetric modulated arc therapy: summary of technical and dosimetric features and early clinical experience. Radiat Oncol. 2010:5:14.

7. Wolff HA, Wagner DM, Conradi LC, Hennies S, Ghadimi M, Hess CF, et al. Irradiation with protons for the individualized treatment of patients with locally advanced rectal cancer: a planning study with clinical implications. Radiother Oncol. 2012;102(1):30-7.

8. Cilla S, Caravatta L, Picardi V, Sabatino D, Macchia G, Digesu C, et al. Volumetric modulated arc therapy with simultaneous integrated boost for locally advanced rectal cancer. Clin Oncol (R Coll Radiol). 2012;24(4):261-8.

9. Parekh A, Truong MT, Pashtan I, Qureshi MM, Martin NE, Nawaz O, et al. Acute gastrointestinal toxicity and tumor response with preoperative intensity modulated radiation therapy for rectal cancer. Gastrointest Cancer Res. 2013;6(5-6):137-43.

10. Samuelian JM, Callister MD, Ashman JB, Young-Fadok TM, Borad MJ, Gunderson LL. Reduced acute bowel toxicity in patients treated with intensity-modulated radiotherapy for rectal cancer. Int J Radiat Oncol Biol Phys. 2012;82(5):1981-7.

11. International Commission on Radiation Units and Measurements. Prescribing, recording, and reporting photon beam therapy. Bethesda, MD: International Commission on Radiation Units and Measurements; 1993.

12. Hodapp N. The ICRU Report 83: prescribing, recording and reporting photon-beam intensity-modulated radiation therapy (IMRT). Strahlenther Onkol. 2012;188(1):97-9.

13. Sobin LH. TNM, sixth edition: new developments in general concepts and rules. Semin Surg Oncol. 2003;21(1):19-22.

14. Dworak O, Keilholz L, Hoffmann A. Pathological features of rectal cancer after preoperative radiochemotherapy. Int J Colorectal Dis. 1997;12(1):19-23.

15. Trotti A, Colevas AD, Setser A, Rusch $V$, Jaques $D$, Budach $V$, et al. CTCAE V3.0: development of a comprehensive grading system for the adverse effects of cancer treatment. Semin Radiat Oncol. 2003;13(3):176-81.

16. Rubin P, Constine LS, Fajardo LF, Phillips TL, Wasserman TH. RTOG Late Effects Working Group. Overview. Late Effects of Normal Tissues (LENT) scoring system. Int J Radiat Oncol Biol Phys. 1995;31(5):1041-2.

17. Shang J, Kong W, Wang YY, Ding Z, Yan G, Zhe H. VMAT planning study in rectal cancer patients. Radiat Oncol. 2014;9(1):219.

18. Fokas E, Liersch T, Fietkau R, Hohenberger W, Beissbarth T, Hess C, et al. Tumor regression grading after preoperative chemoradiotherapy for locally advanced rectal carcinoma revisited: updated results of the CAO/ARO/AIO94 trial. J Clin Oncol. 2014;32(15):1554-62.

19. Hernando-Requejo O, Lopez M, Cubillo A, Rodriguez A, Ciervide R, Valero J et al. Complete pathological responses in locally advanced rectal cancer after preoperative IMRT and integrated-boost chemoradiation. Strahlenther Onkol. 2014;190(6):515-20.

20. De Meerleer GO, Fonteyne VH, Vakaet L, Villeirs GM, Denoyette L, Verbaeys A, et al. Intensity-modulated radiation therapy for prostate cancer: late morbidity and results on biochemical control. Radiother Oncol. 2007:82(2):160-6.

21. Gandhi AK, Sharma DN, Rath GK, Julka PK, Subramani V, Sharma S, et al. Early clinical outcomes and toxicity of intensity modulated versus conventional pelvic radiation therapy for locally advanced cervix carcinoma: a prospective randomized study. Int J Radiat Oncol Biol Phys. 2013;87(3):542-8

22. Jiang ZQ, Yang K, Komaki R, Wei X, Tucker SL, Zhuang $Y$, et al. Long-term clinical outcome of intensity-modulated radiotherapy for inoperable nonsmall cell lung cancer: the MD Anderson experience. Int J Radiat Oncol Biol Phys. 2012;83(1):332-9.

23. Folkert MR, Singer S, Brennan MF, Kuk D, Qin LX, Kobayashi WK, et al. Comparison of local recurrence with conventional and intensity-modulated radiation therapy for primary soft-tissue sarcomas of the extremity. J Clin Oncol. 2014:32(29):3236-41.

24. Bortfeld T. IMRT: a review and preview. Phys Med Biol. 2006;51(13):363-79.

25. Jabbour SK, Patel S, Herman JM, Wild A, Nagda SN, Altoos T, et al. Intensitymodulated radiation therapy for rectal carcinoma can reduce treatment breaks and emergency department visits. Int J Surg Oncol. 2012;2012:891067.
26. Pignol JP, Olivotto I, Rakovitch E, Gardner S, Sixel K, Beckham W, et al. A multicenter randomized trial of breast intensity-modulated radiation therapy to reduce acute radiation dermatitis. J Clin Oncol. 2008;26(13):2085-92.

27. Teoh M, Clark CH, Wood K, Whitaker S, Nisbet A. Volumetric modulated arc therapy: a review of current literature and clinical use in practice. $\mathrm{Br} J$ Radiol. 2011;84(1007):967-96.

28. Hall WA, Colbert L, Nickleach D, Shelton J, Marcus DM, Switchenko J, et al. Reduced acute toxicity associated with the use of volumetric modulated arc therapy for the treatment of adenocarcinoma of the prostate. Pract Radiat Oncol. 2013;3(4):e157-164.

29. Scorsetti M, Navarria P, Mancosu P, Alongi F, Castiglioni S, Cavina R, et al. Large volume unresectable locally advanced non-small cell lung cancer: acute toxicity and initial outcome results with rapid arc. Radiat Oncol. 2010;5:94.

30. Macchia G, Cilla S, Morganti AG, Deodato F, Legge F, Piermattei A, et al. Adjuvant volumetric-modulated arc therapy with simultaneous integrated boost in endometrial cancer. Planning and toxicity comparison. Acta Oncol. 2014;53(2):251-8.

31. Tozzi A, Cozzi L, Iftode C, Ascolese A, Campisi MC, Clerici E, et al. Radiation therapy of anal canal cancer: from conformal therapy to volumetric modulated arc therapy. BMC Cancer. 2014;14:833.

32. Wolff HA, Conradi LC, Beissbarth T, Leha A, Hohenberger W, Merkel S, et al. Gender affects acute organ toxicity during radiochemotherapy for rectal cancer: long-term results of the German CAO/ARO/AIO-94 phase III trial. Radiother Oncol. 2013;108(1):48-54.

33. Francois E, Azria D, Gourgou-Bourgade S, Jarlier M, Martel-Laffay I, Hennequin C, et al. Results in the elderly with locally advanced rectal cancer from the ACCOR12/PRODIGE 2 phase III trial: tolerance and efficacy. Radiother Oncol. 2014;110(1):144-9.

34. Meyerhardt JA, Tepper JE, Niedzwiecki D, Hollis DR, McCollum AD, Brady D, et al. Impact of body mass index on outcomes and treatment-related toxicity in patients with stage II and III rectal cancer: findings from Intergroup Trial 0114. J Clin Oncol. 2004;22(4):648-57.

35. Freedman GM, Anderson PR, Li J, Eisenberg DF, Hanlon AL, Wang L, et al. Intensity modulated radiation therapy (IMRT) decreases acute skin toxicity for women receiving radiation for breast cancer. Am J Clin Oncol. 2006;29(1):66-70.

36. Sun LM, Huang EY, Liang JA, Meng FY, Chang GH, Tsao MJ. Evaluation the consistency of location of moist desquamation and skin high dose area for breast cancer patients receiving adjuvant radiotherapy after breast conservative surgery. Radiat Oncol. 2013;8:50.

37. Mell LK, Kochanski JD, Roeske JC, Haslam JJ, Mehta N, Yamada SD, et al. Dosimetric predictors of acute hematologic toxicity in cervical cancer patients treated with concurrent cisplatin and intensity-modulated pelvic radiotherapy. Int J Radiat Oncol Biol Phys. 2006;66(5):1356-65.

38. Emami B. Tolerance of Normal Tissue to Therapeutic Radiation. Radiother Oncol. 2013;1(1):25-48.

39. Eifel PJ, Levenback C, Wharton JT, Oswald MJ. Time course and incidence of late complications in patients treated with radiation therapy for FIGO stage IB carcinoma of the uterine cervix. Int J Radiat Oncol Biol Phys. 1995;32(5):1289-300.

\section{Submit your next manuscript to BioMed Central and take full advantage of:}

- Convenient online submission

- Thorough peer review

- No space constraints or color figure charges

- Immediate publication on acceptance

- Inclusion in PubMed, CAS, Scopus and Google Scholar

- Research which is freely available for redistribution 